Case Study

\title{
CYCLOPHOSPHAMIDE INDUCED FATAL CYTOPENIA: A CASE OF PARAQUAT POISONING
}

\author{
AJIT SINGH ${ }^{1}$, RAJESH V.2 , SONAL SEKHAR ${ }^{3}$, BARAKUR ANANTHAKRISHNA SHASTRI4, KAVITHA SARAVU ${ }^{5}$
}

1Department of Cardiology, Kasturba Medical College and Hospital, Manipal University, Manipal 576104, India, ${ }^{2}$ Manipal College Of Pharmaceutical Sciences, Manipal University, Manipal, India 576104, ${ }^{3}$ Manipal College of Pharmaceutical Sciences, Manipal University, Manipal, IN 576104, ${ }^{4}$ Department of Medicine, Kasturba Medical College and College, Manipal University, Manipal, India 576104, ${ }^{5}$ Department of Medicine, Kasturba Medical College and College, Manipal University, Manipal, India 576104 Email: ajitjsingh.mcops@gmail.com

Received: 16 Apr 2016 Revised and Accepted: 12 Aug 2016

\begin{abstract}
Paraquat is an effective herbicide widely used in India, but is highly toxic on human exposure. Cyclophosphamide is used as pulse therapy in combination with methylprednisolone for paraquat poisoning management. Neutropenia and thrombocytopenia are the main side effects which may occur with cyclophosphamide in cancer treatment due to bone marrow suppression. Hereby we report a rare case of cyclophosphamideinduced fatal cytopenia in a patient with paraquat poisoning. This is a case of $24 \mathrm{y}$ old male who came to the emergency department of our hospital with a history of alleged consumption of $50 \mathrm{ml}$ of paraquat liquid. On admission, he complained of pain and burning sensation in the throat and retrosternal region. Different treatment modalities, namely, pulse therapy with cyclophosphamide and methylprednisolone; and hemoperfusion were used to manage patient's condition. Within few days, the patient developed severe neutropenia and thrombocytopenia. Despite several blood transfusions, the patient expired due to fatal manifestations of cytopenia.
\end{abstract}

Keywords: Neutropenia, Thrombocytopenia, Pulse Therapy, Pesticide poisoning

(C) 2016 The Authors. Published by Innovare Academic Sciences Pvt Ltd. This is an open access article under the CC BY license (http://creativecommons. org/licenses/by/4. 0/) DOI: http://dx.doi.org/10.22159/ijpps.2016v8i10.12253

\section{INTRODUCTION}

Paraquat is a widely used bipyridyl contact herbicide having good safety records on proper use. Most cases of paraquat poisoning are due to suicidal ingestion of the compound. Pulse therapy with cyclophosphamide (CP) and methylprednisolone is an effective and safe way to treat patients with moderate to severe paraquat poisoning [1]. However; pulse therapy was evaluated as a welltolerated therapy, spontaneously recovered leucopenia being one of the major complications of this. CP is well known to cause myelosuppression (leucopenia, neutropenia, thrombocytopenia and anemia), bone marrow suppression and severe immune suppression which may be fatal [2]. But a short course of $\mathrm{CP}$ as pulse therapy in paraquat poisoning causing febrile neutropenia and thrombocytopenia together is a rare condition. In our knowledge, this is the first paraquat poisoning case being reported, where only 3 $\mathrm{d}$ of $\mathrm{CP}$ pulse therapy induced severe anemia, leucopenia and thrombocytopenia. In spite of giving timely supportive measures, the case turned out to be fatal. Ethical permission from institutional ethical committee was taken to report the case.

\section{Case Report}

A 24 y old male patient was admitted to the emergency department of Kasturba Medical College and Hospital, Manipal on $5^{\text {th }}$ day of alleged selfconsumption of $50 \mathrm{ml}$ of paraquat along with $50 \mathrm{ml}$ of alcohol. He experienced burning and pain in throat and retrosternal region. $\mathrm{He}$ developed jaundice from $2^{\text {nd }}$ day of consumption of the poison.

Table 1: The laboratory values of the patient in the hospital until death. The first column represents the lab parameters and the second column represents their standard values with units. The remaining columns list the lab values on the appropriate day after admission in hospital. On days with a dash in the box, the corresponding lab value was not obtained

\begin{tabular}{|c|c|c|c|c|c|c|c|c|c|}
\hline Lab parameter & $\begin{array}{l}\text { Standard value } \\
\text { and units }\end{array}$ & D1 & D2 & D3 & D4 & D5 & D6 & D7 & D8 \\
\hline Hemoglobin & $13-17 \mathrm{~g} / \mathrm{dl}$ & 8.4 & 7.6 & 7.2 & - & - & 6.0 & 6.5 & 6.2 \\
\hline Hematocrit & $40-50 \%$ & 25.3 & 23.2 & 21.7 & - & - & 17.5 & 18.1 & 17.9 \\
\hline Prothrombin Time & $13.6-16.9 \mathrm{~s}$ & - & - & 17.9 & - & 18.0 & - & - & 18.3 \\
\hline Total Bilrubin & $0.3-1.2 \mathrm{mg} / \mathrm{dl}$ & 12.8 & - & 8.0 & 11.6 & 13.2 & 18.4 & - & 16.5 \\
\hline Direct Bilrubin & $0-0.4 \mathrm{mg} / \mathrm{dl}$ & 10.8 & - & 6.4 & 9.9 & 10.7 & 15 & - & 14.5 \\
\hline AST & $5-35 \mathrm{U} / \mathrm{l}$ & 210 & - & 74 & 145 & 91 & 102 & - & 94 \\
\hline ALT & $10-40 \mathrm{U} / \mathrm{l}$ & 121 & - & 86 & 132 & 106 & 129 & - & 120 \\
\hline ALP & 20-140 IU/1 & 166 & - & 124 & 96 & 140 & 164 & - & 164 \\
\hline Urea (Serum) & $10-40 \mathrm{mg} / \mathrm{dl}$ & 90 & 106 & 113 & 131 & 143 & 118 & 81 & 96 \\
\hline Serum Creatinine & $0.6-1.4 \mathrm{mg} / \mathrm{dl}$ & 4.8 & 5.2 & 2.8 & 2.9 & 1.7 & 1.8 & 1.1 & 1.2 \\
\hline Platelets & $>150 * 10^{3}$ & $170 * 10^{3}$ & - & - & - & 23000 & 20000 & 28000 & 21000 \\
\hline $\begin{array}{l}\text { Leucocytes Count } \\
\text { (WBCs) }\end{array}$ & $4.1-10.9 * 10^{3}$ & 7800 & - & - & - & 2100 & 1700 & 900 & 900 \\
\hline Neutrophils & $45-75 \%$ & 77.3 & - & - & - & 44 & 35 & 27 & 28 \\
\hline Lymphocyte & $15-44 \%$ & 12 & - & - & - & 24 & 30 & 56 & 51 \\
\hline \multicolumn{10}{|c|}{ Arterial blood gas details } \\
\hline $\mathrm{pH}$ & $7.35-7.45$ & - & - & 7.22 & 7.31 & 7.50 & 7.48 & 7.56 & 7.60 \\
\hline $\mathrm{SaO}_{2}$ & $95-99 \%$ & 87.4 & 92.8 & 84.8 & 96.9 & 99.2 & 99.4 & 99.6 & 98.6 \\
\hline $\mathrm{PaCO}_{2}$ & $35-48 \%$ & 16.2 & 30.8 & 31.4 & 33.3 & 27.8 & 21.4 & 27.2 & 26.6 \\
\hline $\mathrm{FiO}_{2}$ & $0.21-1.00$ & - & - & 1.0 & 0.45 & 0.40 & 0.42 & 0.50 & 0.45 \\
\hline
\end{tabular}


Physical examination revealed pallor, icterus and oral ulcers. The vital signs and systemic examination were normal. Laboratory investigation showed normal platelet count and leukocyte count, but low hemoglobin and deranged hepatic and renal function tests [table 1].

The patient was started with pulse therapy of methylprednisolone (dose of $1 \mathrm{~g} / \mathrm{d}$ ) in combination with CP (dose of $1 \mathrm{~g} / \mathrm{d}$ ) from $1^{\text {st }}$ day in hospital for $3 \mathrm{~d}$ to prevent the development of progressive pulmonary fibrosis which could lead to respiratory failure. Mesna was administered to reduce the risk of urinary bladder complications caused by CP. Hemoperfusion was started from $1^{\text {st }}$ day in the hospital and continued for $7 \mathrm{~d}$ to eliminate the paraquat from the body. Empirical antibiotic therapy with piperacillin/ tazobactam $4.5 \mathrm{~g}$ was started from the first day in the hospital. Antiemetic (ondansetron), proton pump inhibitor (omeprazole) and dextrose were continued as supportive therapy along with the pulse therapy. The patient was also resuscitated with inotropes on the first day in the hospital. On $3^{\text {rd }}$ day of admission, the patient developed acute respiratory distress syndrome (ARDS) for which the patient was intubated.

On $4^{\text {th }}$ day of admission, the patient developed hospital-acquired pneumonia with fever and tachypnea. The patient was administered second antibiotic linezolid. On $5^{\text {th }}$ day of admission, hematology reports showed leucopenia and thrombocytopenia. Hematology reports revealed drop in platelets from 150,000 cells $/ \mathrm{mm}^{3}$ to 23,000 cells $/ \mathrm{mm}^{3}$ and leukocyte count from 7800 cells $/ \mathrm{mm}^{3}$ to 2100 cells $/ \mathrm{mm}^{3}$. On $6^{\text {th }}$ day of admission, blood culture report showed the presence of gram-positive bacteria (Streptococcus pneumonia) supportive of pneumonia. Hence teicoplanin was started at the same day instead of linezolid. He was continued with supportive therapies and hemoperfusion.

On $10^{\text {th }}$ day of the paraquat consumption (i.e. $3^{\text {rd }}$ day after completion of pulse therapy) patient's temperature rose, platelet count dropped to 20,000 cells $/ \mathrm{mm}^{3}$ and leukocytes dropped to 900 cells $/ \mathrm{mm}^{3}$ with $27 \%$ neutrophils. Since hemoglobin also dropped to $6.5 \mathrm{~g} / \mathrm{dl}$, the patient was given packed RBC transfusions for $3 \mathrm{~d}$ along with platelets transfusion. On $13^{\text {th }}$ day after the consumption, the patient's condition became critical and eventually succumbed to septic shock and cytopenia. The patient seemed to be improving with respect to renal failure but succumbed to sepsis.

\section{DISCUSSION}

Paraquat is a contact herbicide used worldwide; mostly in India and Sri Lanka. It causes fatal poisoning on human exposure; damages the lungs, kidney, and liver. Usually, paraquat gets absorbed rapidly but incompletely and gets eliminated unchanged in urine within 12-24 h. Clinical features are mainly due to intracellular effects. Paraquat cause toxicity because it involves in redox-cycling and generates the reactive oxygen species (ROS) [3]. Paraquat generates reactive oxygen species which cause cellular damage via lipid peroxidation, activation of nuclear factor kappa-light-chain-enhancer of activated B cells (NF-kB), mitochondrial damage and apoptosis in many organs. Toxicity in most of the body organs occurs because of highly reactive oxygen and nitrite species generation. The lung bears the brunt of injury as paraquat is accumulated in the lung against a concentration gradient $[3,4]$. We can classify the severity of paraquat poisoning in three categories. First, mild poisoning in which patients develop minor and completely curable gastrointestinal symptoms (when patient is found to have $20 \mathrm{mg}$ or less paraquat ions/kg of body weight); second is severe poisoning (20-40 mg paraquat ions/ $\mathrm{kg}$ of body weight) in which patients develop acute renal failure, acute lung injury with progressive pulmonary fibrosis, respiratory failure leading to death in two to three weeks; third, fulminant poisoning ( $>40 \mathrm{mg}$ paraquat ions $/ \mathrm{kg}$ of body weight) in which death occurs because of multiple organ failures, within hours to a few days of consumption $[5,6]$.

The literature suggests that pulse therapy with CP and methylprednisolone may be an effective and safe way to treat patients with moderate to severe paraquat poisoning.
Several studies have looked at the use of CP and steroid therapy. Addo and Poon-King (1986) claimed a $72 \%$ survival rate in 72 patients treated with $\mathrm{CP}(5 \mathrm{mg} / \mathrm{kg} / \mathrm{d}$ to a maximum total of $4 \mathrm{~g})$ and dexamethasone (8 $\mathrm{mg}$ eight-hourly over two weeks) [7]. Lin et al., 1999; reported results of a prospective, randomized study of pulse therapy with cyclophosphamide $(1 \mathrm{~g} / \mathrm{d}$ for $2 \mathrm{~d})$ and methylprednisolone $(1 \mathrm{~g} / \mathrm{d}$ for $3 \mathrm{~d})$ in 142 patients of paraquat poisoning [1]. Pulse therapy with CP and methylprednisolone has strong evidence on the improvement of the prognosis of patients with mild to severe paraquat poisoning. Leucopenia (white blood count $<3000$ ) was the only major complication of pulse therapy and occurred in six of the 16 cases (37-50\%), but in all spontaneous recovery occurred within one week [8]. Pulse therapy is evidenced as safe and well-tolerated therapy to prevent progressive pulmonary fibrosis and respiratory failure. In this case, cytopenia including neutropenia and thrombocytopenia resulted in a fatality. Although studies have reported the possible role of linezolid to cause myelosuppression, it is time dependent and occurs only when it was given for $2 \mathrm{w}$ or more [9]. Our case, the cytopenia is unlikely to be due to linezolid as the patient had just received $3 \mathrm{~d}$ of linezolid.

\section{CONCLUSION}

CP pulse therapy with methylprednisolone is proven safe and also used globally as a treatment of paraquat poisoning. In this case, we cannot conclude the exact course of cytopenia but delayed therapy can be a cause of fatal outcome as the patient reached the hospital on the 5th day. We can take a message home is that we should monitor the hematological parameters closely with CP therapy.

\section{CONFLICTS OF INTERESTS}

All authors have declared no conflicts of interest and this submission was not funded by any person, institution or organization in any way.

\section{REFERENCES}

1. Lin J, Wei M, Liu Y. Pulse therapy with cyclophosphamide and methylprednisolone in patients with moderate to severe paraquat poisoning: a preliminary report. Thorax 1996; 51:661-3.

2. Newstead CG. Cyclophosphamide treatment of paraquat poisoning. Thorax 1996;51:659-60.

3. Saravu K, Sekhar S, Pai A, Barkur AS, Rajesh V, Earla JR. Paraquat-a deadly poison: report of a case and review. Indian J Crit Care Med 2013;17:182-4.

4. Gawarammana IB, Buckley NA. Medical management of paraquat ingestion. Br J Clin Pharmacol 2011;72:745-57.

5. Agarwal R, Srinivas R, Aggarwal AN, Gupta D. Experience with paraquat poisoning in a respiratory intensive care unit in North India. Singapore Med J 2006;47:1033-7.

6. Sabzghabaee AM, Eizadi-Mood N, Montazeri K, Yaraghi A, Golabi M. Fatality in paraquat poisoning. Singapore Med J 2010;51:496-500.

7. Raghu K, Mahesh V, Sasidhar P, Reddy PR, Venkataramaniah V, Agarwal A, et al. Paraquat poisoning: a case report and review of the literature. J Family Community Med 2013;20:198-200.

8. Olson DP, Diaz JA, Jereda JD. A fatal case of paraquat ingestion: clinical course and review of pathophysiology. Med Sci Monit 2010;16:153-6.

9. Gerson SL, Kaplan SL, Bruss JB, Le V, Arellano FM, Hafkin B, et al. Hematologic effects of linezolid: summary of clinical experience. Antimicrob Agents Chemother 2002;46:2723-6.

\section{How to cite this article}

- $\quad$ Ajit Singh, Rajesh V, Sonal Sekhar, Barakur Ananthakrishna Shastri, Kavitha Saravu. Cyclophosphamide-induced fatal cytopenia: a case of paraquat poisoning. Int J Pharm Pharm Sci 2016;8(10):296-297. 